Original paper

\title{
Memory, risk, and regional identity: Assessing the socio-cultural impacts of tornadoes in Oklahoma, USA
}

\section{Ashley Allen ${ }^{1}$}

Received: 16/08/2020 / Accepted: 05/11/2020 / Published online: 26/11/2020

\begin{abstract}
Tornadoes are often seen as a way of life in the Great Plains region of the United States, with many stories of deadly storms originating before the 20th century. Because of this historic connection between people and their environment, residents of states such as Oklahoma develop distinctive sociocultural relationships to extreme weather, particularly associating tornadoes with social memory and regional identity. In this paper, I assert that shared memories of historic tornadoes are impactful to Oklahomans' regional identity as it relates to residents' relationships with risk. Multiple qualitative methods, including interview and archival research were used in order to identify the importance of this relationship to Oklahomans as a social group. Much importance is also placed on connecting the present to the past, and many Oklahomans have adopted tornadoes as a symbol of strength. While memories of these tornadic events do not negate the risks of living in a potentially dangerous environment, they also do not imply that risks should be avoided. Rather, facing these risks is seen as a practice in endurance that many Oklahomans believe they were built to face.
\end{abstract}

Key words: memory, risk, identity, hazards, tornadoes.

\section{INTRODUCTION}

When I interviewed an Oklahoma meteorologist about the importance of tornadoes in Oklahoma, he reiterated the idea that tornadoes and the risks involved are part of Oklahoman

\footnotetext{
${ }^{1}$ Geology and Geography, Ohio Wesleyan University (OH)
} 
identity. Speaking of his own fascination with tornadoes, he said "I always had mixed emotions, because they scared the daylights out of me sometimes, but I really liked it."

The risk of tornadoes and the conscious societal decisions to keep on in the face of these risks are meaningful to many individuals and communities within Oklahoma. Listening to, engaging with, and sharing tornado stories can help people to establish important societal connections to memories of tornadoes past while using learned information to make decisions regarding future tornadic activity. More bluntly, my research shows how, by talking about the weather, Oklahomans have created a relationship to risk that is based on ideals of strength and community rather than apathy or fear.

This paper focuses on the socio-cultural impacts of the five deadliest tornadoes in Oklahoma (see Figure 1), which occurred in Woodward in 1947, Snyder in 1905, Peggs in 1920, Antlers in 1945, and Pryor Creek, colloquially and for the purposes of this paper referred to as "Pryor," in 1942 (see Figure 2). Hilary Geoghegan and Catherine Leyson (2012) contend that researching weather qualitatively lets us understand and consider the day-to-day identities of those effected by extreme events, and how knowledge of everyday weather effects local understanding of extremes. This local understanding is the crux of what makes extreme weather events so culturally significant. Extremes disrupt normal activities and demand immediate attention, and their consequences are immediately meaningful. As Georgina Endfield and Lucy Veale (2017) wrote, "Indeed, while we make history in normal weather, extreme weather shapes history” (7).

Each of the tornadoes discussed is still significant to the cultural fabric of the community it devastated. By understanding what people shared about historic tornadoes and how those that received it engaged with that information, researchers can better understand how historical weather experiences are significant in shaping memories and identities even amongst current residents (Veale, Endfield, and Naylor 2014).

Weather is something that people experience, and these experiences influence culture and identity, though most often those stories are told through the perspectives of physical scientists (Meyer 2014, Endfield and Morris 2012, Geoghegan and Leyson 2012). Human experiences with weather are important for a multitude of reasons, mostly because it is the one thing that every person must deal with every day. Individuals make small and large decisions according to their daily weather report (who among us has found themselves without a necessary sweater or umbrella?). On a larger scale, weather impacts public health, travel, and community and regional economies (Endfield and Veale 2017, Geoghan and Leyson 2012, Peppler 2010, Danielson 1990).

Georgina Endfield and Carol Morris (2012) write that "climate and its cultural significance have, in effect, become decoupled, and popular conceptualisations and discourses of climate, and its manifestations through local weather, have been replaced by a global, and predominately scientific, meta-narrative" (1). This shift in discourse is something that many researchers are trying to correct, because it is also important to understand, especially in the context of extreme weather events such as tornadoes and how they effect memory and identity. 


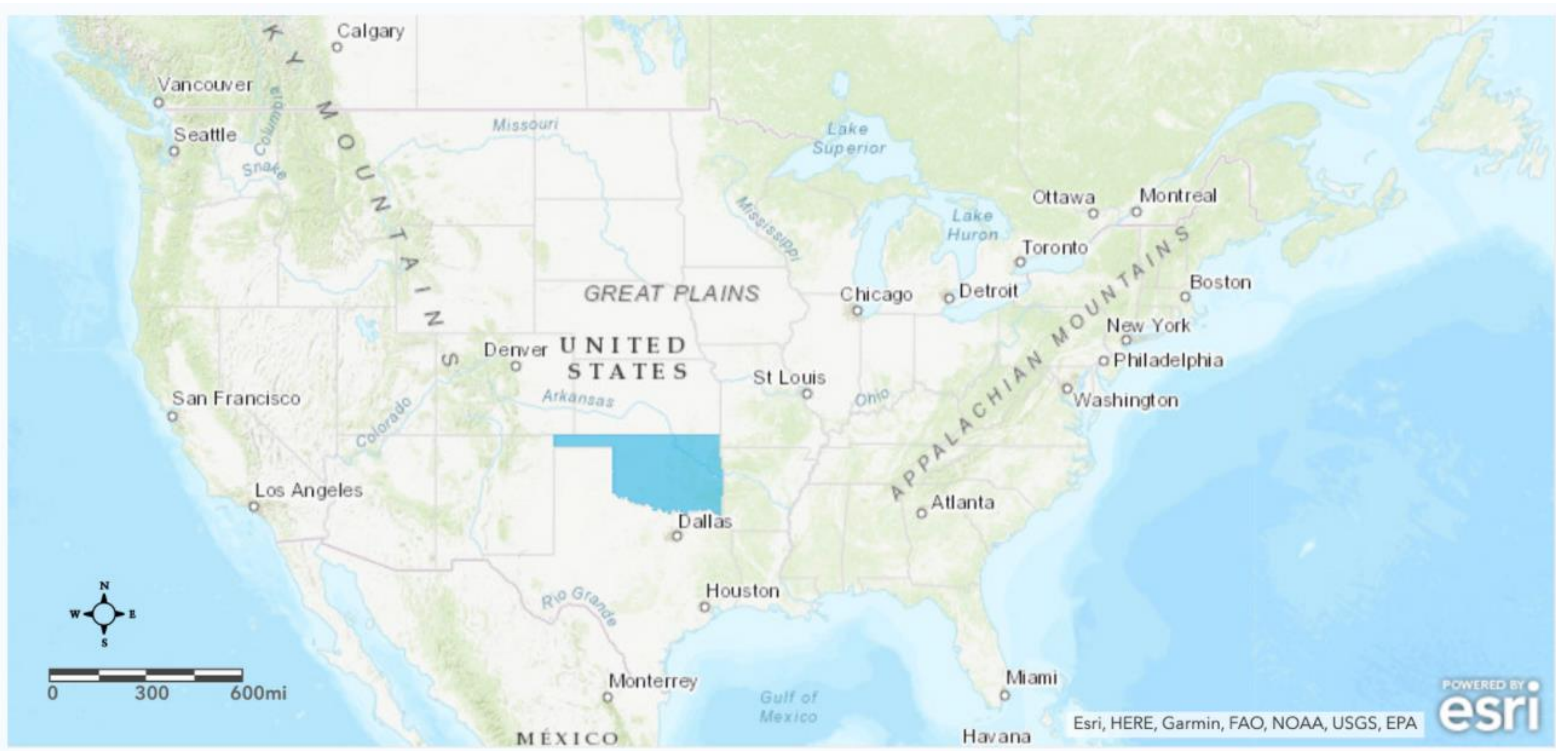

Figure 1. Location of Oklahoma within the United States (cartography by author).

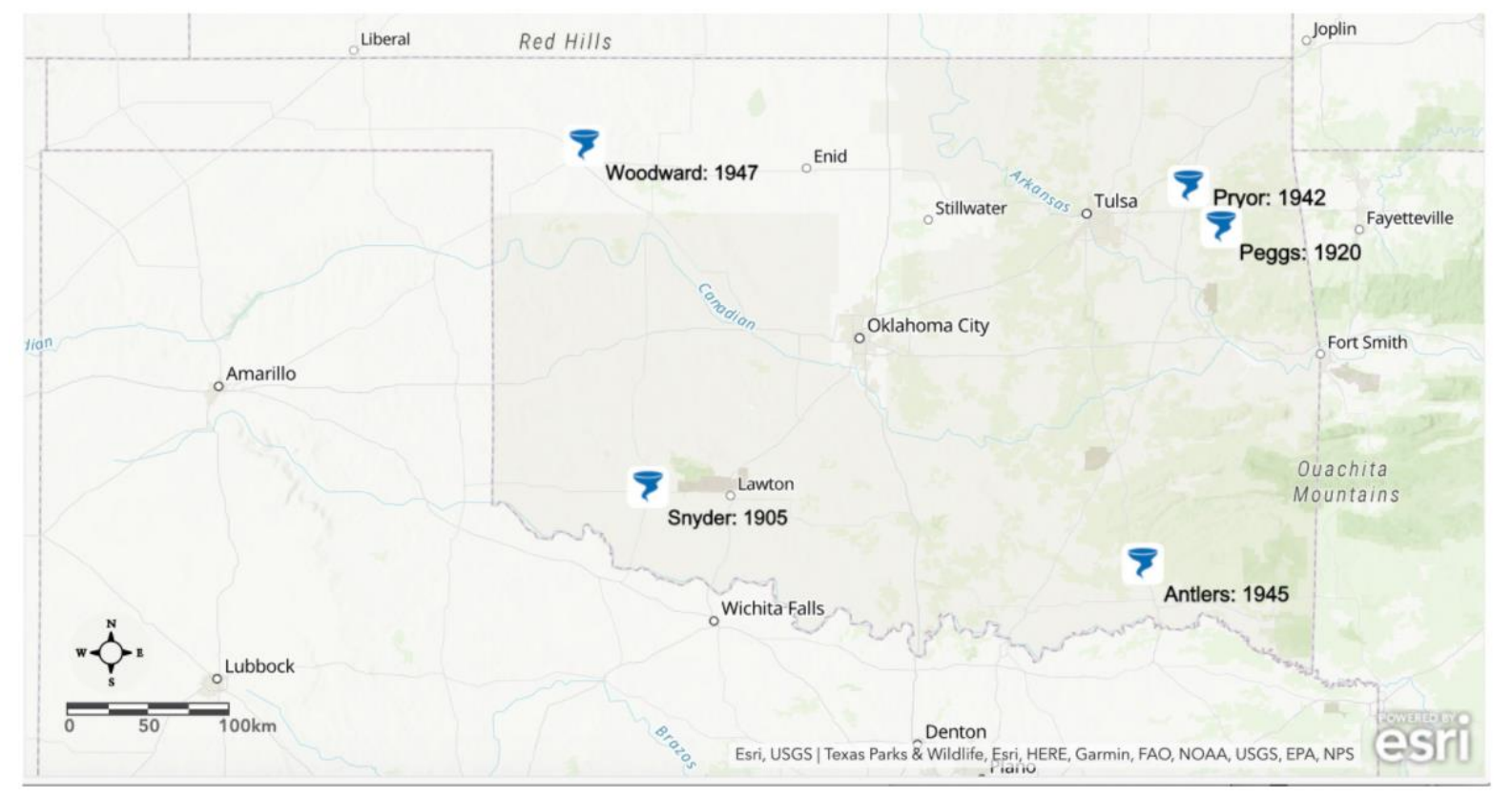

Figure 2. Locations of five towns where Oklahoma's deadliest tornadoes occurred (cartography by author).

In this paper, I focus on the memory work that these tornadoes accomplish through the sharing of individual stories and the creation of community narratives, which impact regional identity. In the context of this research, "memory work" refers to process of working through loss and trauma by revisiting the past, as discussed by Pierre Nora (1989) and Karen Till (2005) among others. This regional identity aligns with a sense of "Oklahomaness" as originally 
outlined by Howard F. Stein and Gary L. Thompson (1991). In this definition, Oklahomaness encompasses what it feels like to be Oklahoman.

In this paper, I outline the creation of "Oklahomaness" through the concepts of reflection (an understanding and awareness of risk), responsibility (an acceptance of risk and sharing of memories and community support), and regional identity (what makes someone Oklahoman in the context of this memory work). Through this framework, I show that tornado stories are meaningful to many individuals and communities within Oklahoma, and the social connections of talking about tornadoes, recent or not, are important to regional identity.

\section{Methods}

Multiple methods were employed for this study to show a complete picture of the significance these tornadoes have in Oklahoma's social memory, which is memory that is articulated and shared within social groups over time, often with the express purpose of creating connections and relationships between individual and group identities (Fentress and Wickham 1992).

The methods used to connect tornado stories to different aspects of memory work included archival research using the Oklahoma Historical Society research archives in Oklahoma City, the Oklahoma State Archives in Oklahoma City, Northeastern Oklahoma State University in Tahlequah, Oklahoma, and the Pryor Public Library, aided by their genealogy librarian, accessing museum and exhibition collections in Woodward, Kiowa County, Jackson County, Antlers, and Pryor, focusing on oral histories, recorded interviews with residents (both written and orated), letters, and autobiographical statements from community members. I also conducted 32 personal interviews in-person and over the phone.

To find interviewees, I placed ads in local newspapers and several Facebook groups, while concurrently hanging physical flyers in community meeting places asking for people to call or e-mail if they were willing to tell their tornado stories. Most of interviewees were survivors of the tornado or relatives of survivors. The other interviewees include members of the community that have grown up hearing stories, historians and museum employees, and a television meteorologist. Throughout this work, pseudonyms were assigned to interviewees who are not public figures and/or did not have previously publicized oral histories or interviews regarding their stories.

\section{Reflection and Responsibility}

The evaluation and management of risk is a social and political action that is often linked to memory. Memories of past hazard events impact risk perception and response, because they are directly linked to community awareness of risks and community understanding that hazards can and probably will occur again (Garnier 2019, Quevauviller, Ciavola, and Garnier 
2017; Svenvold 2005). Writer Mark Svenvold (2005) explained this by saying, "Tornado season in Oklahoma can be seen as a reverse lottery, with everyone wondering Who will it get this year?" (211). This understanding that tornado activity in Oklahoma is not a matter of if, but when, led many residents to assign meaning to these storms in a way others may not. Tornado stories have become ingrained in the cultural fabric of Oklahoma, reminding residents of this risk, but also of the importance of community and coming together.

Geoff Wilson (2012) discussed how these memories can influence communities when it comes to risks and decision making. When communities learn from past hazard events, it speeds up resilient reactions and strategies, helping communities to use their understanding of previous events to mitigate and adapt to extreme events the next time they occur (Wilson 2013). It has also been argued that social memory aids resilience on a community level (Wilson 2015). Joanne Garde-Henson, Lindsey McEwen, Andrew Holmes, and Owain Jones (2017, 2012 as McEwen et. al) actually propose the concept of "sustainable memory" as a type of community-focused memory work that is furthered because of the need to retain knowledge, help future generations understand risk and resilience by contributing to local knowledge of past hazard events (in their case, floods).

The systems by which these memories are shared also impact disaster memorialization, as explained by Boret and Shibayama (2016). They describe this particular type memorialization as "any process that contributes to the preservation of memory of a catastrophe and its victims through tangible or intangible acts of remembrance" (Boret and Shibayama 2016, 438). Their approach includes memories shared through storytelling, as well as other formal and informal memory processes.

Those who live in environments, like Oklahoma, who often find themselves in the wake of tornadic destruction tend to have an intense understanding of and relationship with risk, and they are willing to take risks in order to be good community members (Table 1, Svenvold 2005). This is exemplified by this story from Woodward:

This young kid decided he'd better go and see if he could be of help to somebody. So while he was walking along the railroad track and he discovered two boys was laying off the edge of the railroad track in the mud and dirt. They were stuck in filth. So he went and hunted a piece of tin. It came off of a house or something. But he put it down underneath the boys. He told them he would get help [for them] soon because he couldn't get them out alone. My uncle went out looking too, and when they finally found him, they got the boys out of that stuff and brought them home.

We had no electricity. We had no water. We had no gas. Nothing like that you know. But anyway, we started cleaning those two boys. We found out that they lived in a two story house and their mother hollered and she said "Come on everybody come on there's a tornado!" And they just got to the bottom of the stairs when the wind picked them up.

[The boys] had been wearing jeans, but when they found them the pants they had on were blown into little strips, just half the size of my finger, and they had nothing else 
on. They were literally covered with mud from head to toe. Inside of that mud there were splinters and wood and pieces of glass. They were covered from their hand to their toes. They cried and it was awful. My uncle had a cream can full of water sitting in the house. It was all the water we had. But we used it and went to work and cleaned them up as much as we could. - Anita (Interview Field Notes 2015, 28-30)

Using a household's last bit of water after a major tornado is a risky decision that no one should take lightly. However, this interviewee indicated that it was something she would do for any of her neighbors she felt needed help. This assumption of personal risk for the betterment of someone else is not unique to Oklahoma, but being friendly, helpful, and community oriented in the face of an emergency is part of Oklahoma's regional identity.

This kind of discussion and passing on of local knowledge happens a lot in Oklahoma, as shown here through my interviews. In this context local knowledge (also discussed as community, lay, traditional, Indigenous, or informal knowledge), are concepts understood to be common or ingrained within cultures, and they are increasingly cited as important to the role of understanding extreme weather events, as well as understanding how communities will adapt, understand, and manage future occurrences (Klockow, Peppler, and McPherson 2014, McEwen et al. 2012; Kitahara 2014). Many of my interviewees grew up hearing stories of major storms from older family members, teachers, and members of their community (Table 1). One interviewee, speaking about her father, said "He said it looked like a disaster area and you could hardly find nothing, and nothing really looked like... you know like you would remember it" (Marylin, Interview Field Notes 2015, 111). Though it may seem like a small statement, the simple understanding that these events bring chaos and change the landscape can help prepare future generations for what could come their way (Peppler, Klockow, and Smith 2018; Garde-Henson et. al 2017; Klockow, Peppler, and McPherson 2014)

Randy Peppler, Kimberly Klockow, and Richard Smith (2018) discussed the perception of community risk in Central Oklahoma through the employment of focus groups in Norman, Newcastle, and Moore. Interestingly, many of their subjects equated home with security, perceiving less tornado risk despite scientific evidence. In contrast, my interviewees seemed to embrace the notion of risk as part of the community they chose (Table 1). This assertion alone shows the power of memory work. The interviewees in this study have confronted the most violent tornadoes in history, whether in experience or through social memory processes, and accept that one could hit again (Table 1, Table 2). Further, the cultural significance of these storms encourages people to keep telling their stories, perpetuating the idea that tornado risk is not only something that Oklahomans live with, it's something that makes them Oklahoman in the first place.

I found that one of the key components of Oklahomaness with regard to extreme weather was an acceptance of risk, rather than merely an assumption that tornadoes could occur. The vast majority of interviewees from Woodward not only discussed the tornado of 1947 but went on to compare it to the tornado that hit the town in 2012, with one survivor saying, "it wasn't as bad as the last one, but I always knew it could happen again." Another explained her fear for her family, comparing it to what she had experienced decades before: 
And then when the second one hit here in Woodward [in 2012] my granddaughter was living up on that end of town where she and her three kids had just left and gone to somebody's house when that thing hit. And it got the house they were living in. So they were lucky they weren't hurt. So we're all worried. It was pretty scary for a few years after that. Teresa (Interview Field Notes 2015, 39).

An interviewee from southwest Oklahoma told me a story from his childhood that is exemplary of this kind of understanding. He said:

Woodward psyched us out. ... I remember some of the warnings early on ... and it was a big deal when it happened. ... you know it's scary after that. Seiling finally got hit. I don't know how old I was, but I was in elementary school. And my grandma's house is where everybody would gather on a Saturday night. At grandma's house the men would play cards and drink whiskey and the women would cook pies and cakes or whatever for the next day for Sunday. But the guy living next door to us, just to the west, had a cellar. And one night it was stormy and they blew the sirens. And you know, a town like that is an isolated town. You don't have much communication, but we all would pile on over to the to the cellar and everybody got in there and the wind was really picking up.

Well, my uncle and my granddad decided they were not going to the cellar. They never went to the cellar. They stayed in there playing cards and we were down there in the cellar and you got the big concrete vent I guess, and you could hear it coming. You can you hear this roar. And anyway, then it passed and we opened the door. We found granddad on one side of the cellar door and my Uncle on the other side in the mud face down.

They said they'd been beating on the door. We couldn't hear them because of the storm. And every time after that they were the first to go, so they learned a good lesson there. -- Gary (Interview Field Notes 2015, 68-69)

In so many words, if you get put face down in the mud once; you'll head to the cellar for the rest of your life.

\section{Regional Identity and "Oklahomaness"}

I found that the key components of "Oklahomaness" with regard to extreme weather were both an acceptance of risk, and an understanding that Oklahomans are always resilient and willing to stand together in the face of adversity (Table 1, Table 2). This is apparent in both the vernacular memory of Oklahoma and through formal memory systems. The Oklahoma History Center in Oklahoma City holds and displays many artifacts from tornadoes across the state. The Twister Museum in Wikita pays homage to the movie by showcasing memorabilia including replica Dorothy sensors for sale (a steal for only $\$ 5$ considering the price of working weather forecasting equipment). Venues like the Plains Indian and Pioneers Museum in 
Woodward, the Coo-Y Yah Museum in Pryor, and the Kiowa County Historical Society all have permanent exhibits regarding the Woodward, Pryor, and Snyder tornadoes, respectively. Memorials to tornado victims are present in Woodward, Snyder, and Antlers. Woodward's is downtown, displayed in conjunction with their World War Two and Vietnam Memorials. Snyder dedicated a memorial headstone to unknown victims in the local cemetery. The Pushmataha County Historical Society dedicated the Antlers memorial, which stands on their grounds outside the former railroad depot, which is fitting considering two of their volunteers survived the storm.

Within her work, anthropologist Sunday Moulton (2015) discusses how disaster impacts memory and identity by forming a collective narrative of each event. Though Moulton discusses memory and identity after tornado stories as venues for communities to recover and eventually forget, I claim that remembering those stories, sharing them, and learning from them creates a strong regional bond and support system that makes Oklahomans more adaptable in the face of extreme tragedy.

Table 1. Quotations from interviews reflecting key themes of reflection (an understanding and acceptance of risk) and responsibility (sharing of memories regarding community support).

\begin{tabular}{|l|l|}
\hline Reflection & $\begin{array}{l}\text { "My grandparents lived through [the Peggs tornado]. Every time we had a } \\
\text { bad storm, my grandma would tell me about it; she said everything gets } \\
\text { destroyed." - Molly; Peggs, OK } \\
\text { "It seemed like even the dog remembered. He'd always want to go to the } \\
\text { cellar after [the tornado.]"-Teresa; Woodward, OK }\end{array}$ \\
$\begin{array}{l}\text { "We always watch the radar and always have. My dad thought it might } \\
\text { happen again, then I just got in the habit." - John; Pryor, OK } \\
\text { "We always talk about tornadoes when we talk about home." - Ramona; } \\
\text { Woodward, OK }\end{array}$ & $\begin{array}{l}\text { "... my dad and my two uncles were building our house back. When it was } \\
\text { built, the Red Cross bought our furniture for us." - Alice: Antlers, OK } \\
\text { "My grandpa was a 16-year-old kid and he helped bury the bodies. He said } \\
\text { they wandered around looking but they never found all of them." - David; } \\
\text { Snyder, OK } \\
\text { "The patrol helped keep order. I don't think we had a lot of pilfering or } \\
\text { damage but every [business] had someone there kind of looking after the } \\
\text { store."- Carl; Pryor, OK }\end{array}$ \\
\hline
\end{tabular}


Table 2. Quotations from interviews reflecting regional identity (what constitutes "Oklahomaness" in the context of this memory work).

\begin{tabular}{|l|l|}
\hline $\begin{array}{l}\text { Regional } \\
\text { Identity }\end{array}$ & $\begin{array}{l}\text { "We tell that story every once in awhile. You know there are so many more } \\
\text { tornadoes than there used to be." - Alice: Antlers, OK } \\
\text { "We wrote a book about it, me and a couple of the teachers, we wanted } \\
\text { people to know what happened to our home." - L.O.; Woodward, OK }\end{array}$ \\
$\begin{array}{l}\text { "You know being from Oklahoma, you don't mess around after tornadoes } \\
\text { like that." - Carl; Pryor, OK }\end{array}$ \\
"I grew up in the tornado belt, you might say." - Gary; Oklahoma City, OK \\
"Honey I'm always ready. How long are you staying? Do you want to see \\
where the basement door is out back?" -- Anita; Woodward, OK
\end{tabular}

My own research confirms that narratives explaining the importance of sharing and remembering past tornado stories are incredibly prevalent in Oklahoma, and almost universally involve perseverance, strength, rebuilding, and the support of the community. One of my interviewees said,

People remember where they were when something happens like a before and after. You remember where you were when this happened or that happened, and the Woodward tornado was one of those periods of time. You remember what happened before and then that was an absolute benchmark - going from there. - Teresa (Interview Field Notes 2015, 11)

These benchmarks, and how we communicate them, are what make tornado memories relevant on a social and regional level. When a person or community goes through a traumatic weather event, it raises questions about what that means, what sort of knowledge that brings, and how it changes the community. In terms of loss to the physical landscape, communities work to connect to one another's experiences. Karen Reid, Ruth Beilin, and Jim McLennan (2020) discussed this in terms of community responsibility. They found that people felt a need to continue social traditions while reconstructing new, place-based identities, writing "social memory can only exist in the relationships between individuals and others (or how we imagine ourselves and others) (Reid, Beilin, and McLennan 2020, 42). In Oklahoma, those communities also take great care to ensure that their loved ones are not forgotten. One interviewee said:

To me, if you don't tell [the story] or write it down it's gone. It's gone forever... the main thing is if you don't get it down somewhere or another it's just gone. Nobody will ever know. - L.O. (Interview Field Notes 2015, 11) 
Stories are often as simple as explaining what a tornado looked or sounded like, or how the experience made people feel. In describing what the Woodward tornado was like, one survivor said:

We'll never know all that happened. It was just everything was such a mess. You didn't even know where to look or go first... that was the saddest day of my life. --Ramona (Interview Field Notes 2015, 38)

This kind of discussion is deceptively simple. By telling people how a tornado feels, both physically and emotionally, listeners become privy to explicit information that otherwise would be unavailable outside of experience. By continuing the tradition of telling stories of past events, the idea that a tornado could hit at any time has weaved its way into the collective narrative of many communities (Table 2). This was exemplified in many of my interviews, like this one, which was recalled by many residents of Pryor, but quoted here from my interview with the victim's cousin:

During the storm, my cousin got swept away. He was three months old and just got ripped out of my aunt's arms. They thought they lost him and were really torn up about it. Turns out, the wind carried him seven miles out of town, and a couple found him on their property. The roads were blocked so they just took care of him for a week or so until they could take him back to town. He wasn't hurt or anything. He just went cross-eyed for a bit, but those straightened out eventually. -Jeff (Interview Field Notes 2015, 102)

Moreover, stories often highlight the actions of community members in helping their fellow residents have the capacity to alter the way a person feels about or sees themselves within their community. In many of my interviews with survivors, interviewees discussed their experiences in the context of their interactions with members of the community like this one, also from Pryor:

Well I know when I first knew we were in trouble. My brother, Bob, and I were sitting out in the car in front of the bank. It wasn't raining that hard even. I turned looked out the window and saw the top had blown off the grain elevator and went about three or four blocks. I turned to Bob and said "We better get down. Here it comes!" He said "What?" and I said, "the elevator top!" I did no more than get that out and Bob jumped on top of me right before that thing hit the top of our car. I was in the floorboard. Bob said he couldn't have beat me down [further]. That was a scary time. I don't know how to tell you how it feels.

Before, the town was how it had always been. Everybody knew about everybody in it. And after that it felt different. It was just a couple minutes and Tom Miller had come out [of the bank] and was trying to get that top off [our car]. People were coming from down Main Street to [get] Bob and I [out]. - Toby (Interview Field Notes 2015, 97-98)

The act of surviving these storms has become a point of pride for many communities as well, like Snyder, whose high school mascot is still the Cyclone, a symbol of strength, power, and 
community pride in the face of tough opposition. One interviewee, the grandson of a survivor who grew up in Snyder, told me that even when he was growing up in the 1960s, Snyder was known as the "tornado town," saying "My mom would take me to [the nearest city] to get my hair cut and the barber would say 'Snyder! That's the tornado town!' It always made me feel kind of cool to be from here" (A.J. Interview Field Notes 2015, 134).

Mike Hulme (2016) discussed the fear some people experience when living in volatile climates that are prone to extreme events. What is interesting about Oklahoma is that many individual fears seem to be calmed by the idea that whatever happens, their community will help take care of them. This sense of community togetherness is part of the cultural fabric of Oklahoma, and the concept was reiterated by many interviewees when discussing past and future tornado events.

Only two survivors I interviewed discussed being fearful of storms due to their past experiences, and both followed up those assertions by telling me about their shelter plans. Multiple interviewees indicated their homes, basements, and storm shelters were available to me should the need arise, with one saying:

Yes. You know we just always go to the cellar because we're trying to save our life and our children and everything. We know everybody. All of our neighbors know everybody. Not so long I had a whole yard full of people out here getting in the cellar.

All the neighbors around here didn't have storm shelters so right when they move in, I tell them their welcome to come if they need it. The back door is always unlocked. I would never lock the door if I thought a storm was coming. You can look and see where it is if you need it. - Ramona (Interview Field Notes 2015, 34).

This type of support for other community members, even when they are strangers, exemplifies the regional ideas of community and unified strength when facing these storms.

\section{CONCLUSIONS}

Memory work and memorialization, both formal and informal, shows how social memory reaches out, affects, and changes how Oklahomans become part of a community that understands tornadoes even if they do not experience them. By focusing on the memory work that is applicable to different extreme weather and natural hazard events, I answer the question of how community building is possible and how memory can create a sense of community understanding.

This work builds on hazards research to show that not only is memory work important in terms of learning about extreme hazard events, but it also helps people to adapt and mitigate future events through connecting to community. These connections range from local governments recognizing anniversaries of major events, to the commissioning of memorials and exhibits, to the act of past tornado survivors reaching out to their own or other communities 
in times of need. Agencies like the National Weather Service and/ or the Federal Emergency Response Administration could also benefit from these local connections. By gaining a better understanding of local knowledge, belief systems, and social structures, agencies can understand why the public does or does not respond to crucial warning systems or mitigation efforts. The lack of formal avenues for sharing tornado stories may be one of the reasons that memory is often overlooked in formal risk management procedures. By opening up lines of communication between community members, hazards specialists, and government stakeholders, a more holistic type of hazard mitigation that incorporates local knowledge of risk could be employed. This could be done through the creation of focus groups, discussions with representatives appointed from community groups, informal sharing, or a combination of the three.

To many Oklahomans, tornadoes are more than just extreme weather events or risky rare occurrences, they are an integral part of who they are and where they come from. Much importance is placed on assigning meaning to the past and talking about it in the present. With tornadoes, what should be a terrifying loss becomes an example of how Oklahomans identify as community builders, helpers, and always "OK".

\section{REFERENCES}

Boret, P. S., Shibayama, A. (2016). Archiving and Memorializing Disasters. Report of a UN International Workshop, Journal of Disaster Research, 11(3).

Danielson, L. (1990) Tornado Stories in the Breadbasket: Weather and Regional Identity. B, Allen and T. J, Schlereth (Eds.). Sense of Place: American Regional Cultures (pp. 28-39). Lexington, Kentucky: The University Press of Kentucky.

Endfield, G., and Morris, C. (2012). Cultural spaces of climate. Climactic Change, 113 (1), 14.

Endfield, H. G. and Veale, L. (2017). Climate, culture, and weather. Endfield, G., and Veale, L (Eds.). Cultural Histories, Memories, and Extreme Weather (pp. 1-15). London: Routledge.

Fentress, J. and Wickham, C. (1992). Social memory. London: Blackwell.

Garde-Hansen, J., McEwen, L., Holmes, A. and Jones, O. (2017). Sustainable flood memory: Remembering as resilience. Memory Studies, 10(4), 384-405.

Garnier E. (2019). 'Lessons learned from the past for a better resilience to contemporary risks’, Disaster Prevention and Management, 28(6), 778-795.

Geoghegan, H., and Leyson, C. (2012). On climate change and cultural geography: farming on the Lizard Peninsula, Cornwall, UK. Climactic Change, 113 (1), 55-66.

Hulme, M. (2016). Weathered: cultures of climate. SAGE Publications. 
Kitahara, I. (2004), Exhibition on «Documenting disaster: natural disasters in Japanese history 1703-2003». Annals of Geophysics, 47, 909-911.

Klockow, K., Peppler, R. , and McPherson, R. (2014). Tornado folk science in Alabama and Mississippi in the 27 April 2011 tornado outbreak. GeoJournal, 79, 791-804.

McEwen, L., Krause, F., Jones, O., and Garde-Henson J. (2012). Sustainable flood memories, informal knowledge, and the development of community resilience to future flood risk. In Flood Recovery, Innovation and Response III eds. D. Proverbs, S. Mambretti, C. A. Brebbia, \& D. De Wrachien. Ashurst, Southampton, UK: WIT Press.

Meyer, B. W. (2014). Americans and Their Weather: Updated Edition. New York: Oxford University Press.

Moulton, M. S. (2015). How to Remember: The Interplay of Memory and Identity Formation in Post-Disaster Communities. Human Organization, 74 (4), 319-328.

Nora, P. (1989) Between memory and history: Les lieux de mémoire. Representations. 7-24.

Peppler, A. R. (2010). “Old Indian Ways” of Predicting the Weather: Senator Robert S. Kerr and the wWnter Predictions of 1950-51 and 1951-52. Weather, Climate and Society, 2(3), 200-209.

Peppler, A. R., Klockow, E. K. and Smith, D. R. (2018). Hazardscapes: Perceptions of tornado risk and the role of place in central Oklahoma. J. S, Smith (Ed). Explorations in Place Attachment (pp. 33-45). London: Routledge.

Quevauviller P, Ciavola P and Garnier, E (Eds.). (2017). Management of the Effects of Coastal Storms: Policy, Scientific and Historical Perspectives. Chichester: John Wiley \& Sons.

Reid, K., Beilin, R. and McLennan, J. (2020). Communities and responsibility: Narratives of place-identity in Australian bushfire landscapes. Geoforum, 109, 35-43.

Stein, F. H. and Thompson, L. G. (1991). The sense of Oklahomaness: Contributions of Psychogeography to the Study of American Culture. Journal of Cultural Geography. 11(2), 63-91.

Svenvold, M. (2005). Big Weather: Chasing Tornadoes in the Heart of America. New York: Henry Holt and Co.

Till, K. 2005. The New Berlin: Memory, Politics, Place. Minneapolis: University of Minnesota Press.

Veale, L., Endfield, G. and Naylor, S. (2014). Knowing weather in place: the Helm Wind of Cross Fell. Journal of Historical Geography, 45, 25-37. 
Wilson G. A. (2012). Community Resilience and Environmental Transitions. London: Routledge.

Wilson G. A. (2013). Community resilience, social memory and the post-2010 Christchurch (New Zealand) earthquakes. Area 45(2), 207-215.

Wilson G. A. (2015). Community Resilience and Social Memory. Environmental values, 24 (2), 227. 